\title{
Mini-Review
}

\section{In the Footsteps of Scribonius Largus, a Pioneer of Clinical Pharmacy in Ancient Rome}

\author{
Christos Tsagkaris ${ }^{*}$ \\ Anna Loudovikou 2 \\ Dimitrios V. Moysidis 3 \\ Andreas S. Papazoglou 3 \\ Konstantinos Kalachanis 4 \\ ${ }^{1}$ Faculty of Medicine, University of \\ Crete, Rethymnon, Heraklion, Greece \\ ${ }^{2}$ Faculty of Philosophy, Aristotle \\ University of Thessaloniki, \\ Thessaloniki, Serres, Greece \\ ${ }^{3}$ Faculty of Medicine, Aristotle \\ University of Thessaloniki, \\ Thessaloniki, Serres, Greece \\ ${ }^{4}$ New York College, Athens, Central \\ Athens, Greece \\ *email: chriss20x@gmail.com \\ Keywords: \\ Ancient Rome \\ Clinical pharmacology \\ Ethics \\ History of pharmacy
}

\begin{abstract}
Clinical pharmacy involves pharmacists in direct patient care concerning optimizing medicines and promoting health awareness and disease prevention. The whereabouts of the field can be traced to Scribonius Largus, a renowned physician and pharmacist in ancient Rome. Although Largus served as an imperial physician, he has also been an exemplary pharmacist authoring a comprehensive pharmacognosy textbook and dedicated a big part of his life to improving pharmacotherapy and advancing ethics in the field. Revisiting his contributions provides valuable lessons for contemporary clinical pharmacists.
\end{abstract}

Received: June 19th, 2021

Accepted: August 5th, 2021

Published: August 30th, 2021 (http://creativecommons.org/licenses/by-sa/4.0/). DOI: https://doi.org/10.33084/bjop.v4i3.2360

\section{INTRODUCTION}

Ancient Rome was founded in the $8^{\text {th }}$ century BC in central Italy. It grew from a small city to an empire extending from Great Britain to Mesopotamia and Morocco at the peak of its reign during the following centuries ${ }^{1}$. The history of ancient Rome is divided into three distinct periods: the period of Kings (625-510 BC), the republican period (510-31 $\mathrm{BC})$, and the imperial period starting on $31 \mathrm{BC}$. The Goths sacked Rome itself in 410 AD, but the Roman Empire ended in 1453 AD with the fall of Constantinople, the capital of the eastern part of the empire ${ }^{2-4}$.

Imperial Rome became the political, financial, and cultural epicenter of the ancient world, bringing together the medicinal traditions of ancient Greece, Egypt, the Middle East, North Africa, and Western Europe. Anatomy and surgery advanced due to the needs of gladiators and soldiers. Significant progress was made concerning public, occupational health, and sanitation because of the creation of big urban centers. The healthcare workforce of the empire gained experience 
from infectious outbreaks emerging within the imperial territory or spread by populations crossing the border 5 . The pharmacy was rather empiric. Eminent physicians and scientists such as Galen and Plinius provided written accounts of pharmacotherapy and pharmacognosy at the time. In many cases, physicians acted as pharmacists preparing and administering formulations suitable to the diagnoses they made. They would use natural compounds of either animal or plant origin. However, it was within the power of such practitioners to amend the documented pharmacotherapies or invent new ones6,7. Frequently, this would lead to risky practices because folk or fraudulent practitioners would provide therapies of their own, exploiting the need of people to find a cure. Emperors and the nobility would employ the most capable physicians and pharmacists and provide them with the means to practice their treatment skills at individual or population levels. Scribonius Largus was the physician-pharmacist of Emperor Claudius, who reigned between 41 and $53 \mathrm{AD}$,9. In an era when the roles of physicians and pharmacists were hardly distinct, Largus made significant contributions in summarizing the pharmacognosy of his time, prompting evidencebased pharmacotherapy and related policy and ethics ${ }^{10}$. The present review aims to present the biography of Scribonius Largus and highlight his contribution to clinical pharmacy in his era and in modern times.

\section{BIOGRAPHY OF SCRIBONIUS LARGUS}

Scribonius Largus (14-54 AD) was a physician of Greek origin who served in the court of Emperor Claudius as a personal physician (10-54 AD) and also accompanied him on his campaign in Britain ${ }^{11}$. In 47 AD, Gaius Julius Callistus, an imperial statesman, requested him to put together a list of pharmaceutical preparations covering the known disease spectrum of the period. Little is known about the whereabouts of Largus, his family background, his life events, or his death. Information about him derives from the writings of physicians, philosophers, or historians. Although some scholars consider him a fictional character, the fact that prominent Greco-Roman physicians and authors, such as Galen, mention him in their works proves his existence ${ }^{12}$. It is worth note, however, that Largus, apart from his contribution in medicine and clinical pharmacy, is well known for his contribution in the field of Medical Ethics, which also proposes a code of conduct for physicians which includes concepts such as mercy and humanity ${ }^{13}$.

\section{THE CONTRIBUTION OF SCRIBONIUS LARGUS TO CLINICAL PHARMACY}

\section{An innovative pharmaceutical textbook}

The basis of Largus's contribution to the clinical pharmacy is his book De compositione medicamentorum liber (Latin, Book of Medicinal Prescriptions). This consists of 271 prescriptions (compositiones) attached to specific medical conditions, syndromes, or symptoms. The majority of them were developed or adapted by him, although he recognizes that his knowledge derived from the texts of eminent physicians and the teachings of his tutors and colleagues. He also included traditional remedies. Grace to his Greek origin, Largus could comprehend medical and pharmaceutical textbooks in both Greek and Latin ${ }^{14}$. A significant number of Greek textbooks, and particularly the Corpus Hippocraticum, a collection of 60 scholarly works authored by Hippocrates and his disciples, contained observations of patients and their outcomes following the administration of particular treatment regimens or food-drug interactions, providing a great source of evidence for Largus ${ }^{15}$.

The original book of Largus has not been saved; however, the bulk of its content was transferred to the writings of Marcellus Empiricus, De Medicamentis Empiricis, Physicis, et Rationabilibus (On Empirical, 
Physical and Rational Pharmacotherapy, 410 AD). Marcellus has brought some corrections to the text of Largus based on the knowledge of his time. Because of this, the available prescriptions might include some anachronisms. Nonetheless, this does not disqualify the contribution of Largus in compiling an up-to-date comprehensive and comprehensible guide of pharmacotherapy for physicians-pharmacists ${ }^{16}$. Moreover, elements from his studies can be retrieved from the famous Greek physician Galen (129-216), who makes many references to his achievements ${ }^{17}$.

\section{Largus as a clinical pharmacist and practitioner}

Largus made the best of his proximity to the imperial court and its ample resources to collect as much information as possible from both written and oral sources. He was preparing and administering state-ofthe-art treatments to restore the health of the emperor and the Roman aristocracy. Despite the initial suspicions against him as a Greek physician who would attempt to harm the roman nobility, his skills were eventually appreciated and praised ${ }^{18}$

His ability to thrive as a practitioner and researcher in such a competitive environment as the imperial court suggests combining scientific knowledge with hard and soft skills. His position increased the credibility of his prescriptions and enabled them to be disseminated throughout the empire and improve pharmacotherapies of the time. Interestingly, his writing style is straightforward with extensive colloquialisms, making his knowledge accessible to physicians - pharmacists with lesser erudite formation. This has also been useful for memorization given the scarcity of textbooks and the practical difficulty of carrying them. Although the duties and roles of physicians and pharmacists were not distinct in his era, Largus illustrated the need for common ground. With his work, it became evident that a good command of pharmacology is necessary for medical practitioners $^{19}$.

It is also worth noting that his practices went beyond the conventional approaches of his era. He was well aware of the limitations of herbal preparations in treating chronic pain and went one step forward to introduce neurostimulation as a treatment of persistent headaches ${ }^{20}$. Largus had also applied neurostimulation to the treatment of arthritis, gout, and musculoskeletal pain. He suggested that a live black torpedo (eel) should be placed under feet at the onset of arthritic pain. To maximize the efficacy of the treatment, he recommended that the patient stand on a moist shore washed by the sea, and they should stay like this until their foot and lower extremity up to the knee is numb. According to him, this would relieve pain or even prevent the exaggeration of painful symptoms if performed early enough ${ }^{21}$. His approach indicates his effort to identify and treat the cause of the condition. Current knowledge has verified the efficacy of electrical stimulation in treating pain and spasticity resistant to pharmacotherapy ${ }^{22,23}$.

\section{The contribution of Largus to scientific integrity and} ethics

The work of Largus has helped to set the boundaries between irrational pharmacotherapy and denial of pharmacotherapy among the practitioners of his time, as illustrated in Figure 1. Largus's recommendations for disease-specific regimens consisted of a response to his colleagues that would downsize the contribution of pharmacotherapy, claiming that time, nature, or supernatural powers would eventually heal the patients. In this context, Largus confronted other physicianpharmacists, such as Ambrosius, who supported the misconception that the therapeutic potential of a given drug stemmed from its preparation by a man who would not wear an iron ring and would only use a stone $\operatorname{mortar}^{12}$. 
Largus probably used his prestige in order to overcome his opponents and their infamous beliefs and practices. Other physician-pharmacists would not be able to do so, even if they shared his commitment to the best available evidence. Largus made the best out of his affiliation with his era's stakeholders. Evidently, he had a good grasp of the bigger picture of power dynamics beyond his field. On top of this, the fact that he did not use this affiliation to promote his agenda or create an extensive memorial of his name indicates his ethical qualities. He vigorously attempted to include the same qualities in his written patrimony to future generations stating that "all men and Gods, in fact, should despise any physician whose heart is not full of humanity and mercy according to the purpose of his profession"24. It appears that Largus must have been a competent and upstanding scientist ${ }^{3}$.

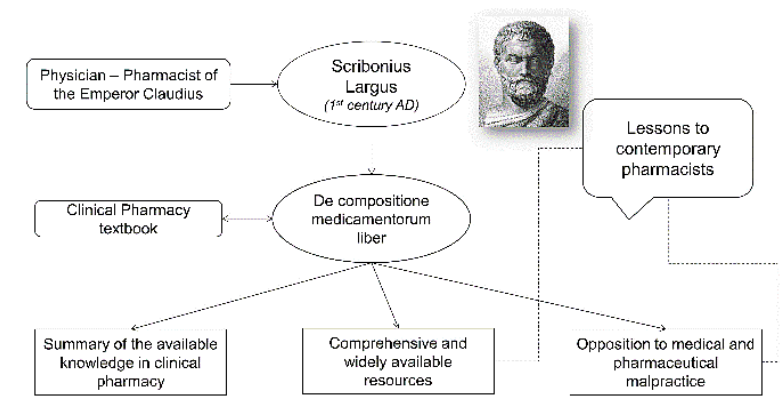

Figure 1. The contribution of Scribonius Largus to scientific integrity and ethics

\section{CONCLUSION}

Nowadays, Largus can be regarded as a role model for contemporary clinical pharmacists and healthcare workers in general. In his footsteps, these scientists need to contribute to improving their field with ethically conducted scholarly work. It is also crucial to develop a good understanding of the power dynamics, in the publishing industry, in the media, and even in politics in order to combat misinformation and malpractice in realworld settings.

\section{ACKNOWLEDGMENT}

None.

\section{AUTHORS' CONTRIBUTION}

Christos Tsagkaris: conceptualization, writing and revising. Anna Loudovikou: data collection, writing. Dimitrios V. Moysidis: writing and revising. Andreas S. Papazoglou: writing and revising. Konstantinos Kalachanis: conceptualization, revising. All authors approved the final version of the article.

\section{DATA AVAILABILITY}

None.

\section{CONFLICT OF INTEREST}

The authors declare no conflict of interest.

\section{REFERENCES}

1. Aldrete GS. History of the Ancient World: A Global Perspective. Virginia: The Great Courses; 2011.

2. Milwaukee Public Museum. The Roman Empire: A Brief History [Internet]. Milwaukee: Milwaukee Public Museum; 2021. Available from: https:/ /www.mpm.edu/researchcollections/anthropology/anthropology-collectionsresearch/mediterranean-oil-lamps/roman-empirebrief-history

3. Del Castillo FF. Scribonius Largus. Hektoen Int. 2016;8(2). Available from: https:/ /hekint.org/2017/01/30/scribonius-largus/

4. Cartwright M. 1453: The Fall of Constantinople [Internet]. Quebec: World History Foundation; 2018. Available from: https:/ /www.worldhistory.org/article/1180/1453the-fall-of-constantinople/

5. Faria MA. Another medical journey to ancient Rome and Roman medicine with medical historian Plinio Prioreschi, MD, PhD. Surg Neurol Int. 2015;6:104 
6. Masic I, Skrbo A, Naser N, Tandir S, Zunic L, Medjedovic $S$, et al. Contribution of Arabic Medicine and Pharmacy to the Development of Health Care Protection in Bosnia and Herzegovina - the First Part. Med Arch. 2017;71(5):364-72. doi:10.5455/medarh.2017.71.364-372

7. Ekor M. The growing use of herbal medicines: issues relating to adverse reactions and challenges in monitoring safety. Front Pharmacol. 2013;4:177. doi:10.3389/fphar.2013.00177

8. Cambiaghi M, Sconocchia S. Scribonius Largus (probably before 1CE-after 48CE). J Neurol. 2018;265(10):2466-8. doi:10.1007/s00415-018-8739-5

9. Zunic L, Skrbo A, Dobraca A. Historical Contribution of Pharmaceutics to Botany and Pharmacognosy Development. Mater Sociomed. 2017;29(4):291-300. doi:10.5455/msm.2017.29.291-300

10. Stephens MDB. The Dawn of Drug Safety. $3^{\text {rd }}$ ed. Hampshire: George Mann Publications; 2012.

11. Thomas LR. The dental aspects of the "Compositiones medicamentorum" of Scribonius Largus: a glimpse of dental treatment in the 1st century A.D. Bull Hist Dent. 1978;26(1):21-7

12. Nutton V. Ancient Medicine. 2nd ed. London: Routledge; 2012.

13. Baker R. Medical Ethics, History of. In: Chadwick R, Callahan D, Singer P. Encyclopedia of Applied Ethics. $2^{\text {nd }}$ ed. Massachusetts: Academic Press; 2012. p. 61-9.

14. Nutton V. Scribonius Largus, the unknown pharmacologist. Pharm Hist. 1995;25(1):5-8

15. Witkamp RF, van Norren K. Let thy food be thy medicine....when possible. Eur J Pharmacol. 2018;836:102-14. doi:10.1016/j.ejphar.2018.06.026

16. Lehmann Y, Lehmann H. [Pharmacology in ancient Rome. First appearance, development, extension]. Rev Hist Pharm. 2015;62(384):447-58

17. Galenus C. De compositione medicamentorum secundum locos libri X. ed C.G. Leipzig: Knobloch; 1826

18. Bliss SE. A Lesson from Greek Physician, Scribonius Largus [Internet]. Burlington: The University of Vermont;2013. Available from: https://www.uvm.edu/news/story/lesson-greekphysician-scribonius-largus
19. Jocks IT. The Compositiones Medicamentorum of Scribonius Largus [thesis]. Glasgow: University of Glasgow; 2013

20. Rajapakse T, Kirton A. Brain Stimulation Applications in Pediatric Headache and Pain Disorders. In: Kirton A, Gilbert D. Pediatric Brain Stimulation: Mapping and Modulating the Developing Brain. $1^{\text {st }}$ ed. Massachusetts: Academic Press; 2016. p. 375-397

21. Tsoucalas G, Karamanou M, Lymperi M, Gennimata $\mathrm{V}$, Androutsos G. The "torpedo" effect in medicine. Int Marit Health. 2014;65(2):65-7. doi:10.5603/imh.2014.0015

22. Matis GK. Spinal Cord Stimulation Therapy: New Technological Advances in Treating Chronic Pain. Nurs Stud Pract Int. 2019;2(2):1012

23. Andrade $P$, Heiden $P$, Visser-Vandewalle V, Matis G. $1.2 \mathrm{kHz}$ High-Frequency Stimulation as a Rescue Therapy in Patients with Chronic Pain Refractory to Conventional Spinal Cord Stimulation. Neuromodulation. 2021;24(3):540-5. doi:10.1111/ner.13278

24. Faria MA. Religious morality (and secular humanism) in Western civilization as precursors to medical ethics: A historic perspective. Surg Neurol Int. 2015;6:105. doi:10.4103/2152-7806.158894 